\title{
Seven-year Survival Rate of On-line Hemodiafiltration
}

\author{
Jung-Hwan Yoon ${ }^{*}$ and Nam-Ho Kim ${ }^{\dagger, * *}$ \\ Department of Internal Medicine, Chonnam National University Hospital, Gwangju 61469, Korea
}

\begin{abstract}
Conventional high-flux hemodialysis (HD) is not as good as normal kidney function. Morbidity and mortality rates of patients receiving HD are still very high. To increase mid-to-large molecule clearance by combining diffusion and convection, on-line hemodiafiltration (HDF) is required. The objective of this study was to compare long-term survival rate of patients treated with on-line HDF to those who received conventional high-flux HD by reviewing data from Chonnam National University Hospital (CNUH). We selected patients who attended the 'CUNH dialysis center' and agreed to participate in the study. Overall, 40 patients with ESRD switched from high flux HD to on-line HDF or started on-line HDF from August 2007 to December 2009. Additionally, a total of 42 patients receiving conventional high-flux HD during the same period were enrolled. We then reviewed long-term survival rate of patients receiving on-line HDF over the next seven years. When we compared survival rates for seven years, the survival rate of the group receiving on-line HDF was $65 \%$ (26/40) while that of the group receiving the conventional high-flux HD was 54.8\% (23/42). Although the number of patients was small to see survival difference clearly by one specific dialysis modality, there was somewhat difference in survival rate between the two groups. Indicators such as anemia, calcium-phosphate metabolism, nutritional status, treatment adequacy, and hospitalization were also improved in the group receiving HDF. Overall, results of our study showed beneficial effects of on-line HDF on clinical outcomes and survival in chronic HD patients.
\end{abstract}

Key Words: Hemodiafiltration, Convection, Renal dialysis, Kidney failure

\section{INTRODUCTION}

Progressive growth of chronic renal failure and end-stage renal disease (ESRD) in the aging population is causing serious health concern because mortality and decreased quality of life are associated with these conditions. These patients have decreased quality of life for many reasons, including infection and cardiovascular disease. Discomfort associated with dialysis is also an important factor that influences mortality. In patients with ESRD, cardiovascular diseases are the most important causes of morbidity and mortality, accounting for about $50 \%$ of deaths among these patients. Degradation of physical function of the kidney is the underlying cause of the morbidity and mortality. Most patients who experience kidney failure undergo dialysis (Moura et al., 2014; Jean et al., 2015).

Hemodialysis (HD) achieves extracorporeal removal of waste products such as creatinine, urea, and free water from the blood when kidneys are in a state of renal failure. However, the efficiency of conventional high-flux HD is not as good as that of normal kidneys. Thus, patient morbidity and mortality rates are still very high (Smirnov et al., 2013). Conventional high-flux HD techniques are based on the cap-

Received: December 11, 2018 / Revised: December 27, 2018 / Accepted: February 12, 2019

*MD, ${ }^{* *}$ Professor.

†Corresponding author: Nam-Ho Kim. Department of Internal Medicine, Chonnam National University, Gwangju 61469, Korea. Tel: +82-62-220-6270, Fax: +82-62-225-8578, e-mail: nhk111@jnu.ac.kr

(C) The Korean Society for Biomedical Laboratory Sciences. All rights reserved.

(C) This is an Open Access article distributed under the terms of the Creative Commons Attribution Non-Commercial License (http://creativecommons.org/licenses/by-nc/3.0/) which permits unrestricted non-commercial use, distribution, and reproduction in any medium, provided the original work is properly cited. 
acity of molecules to diffuse across a semi-permeable membrane which allows adequate clearance of low-molecularweight particles. However, its clearance for moderate and large sized molecules is considerably less adequate (Jones et al., 2012). On-line hemodiafiltration (HDF) can be employed to compensate for these shortcomings of the conventional high-flux HD by increasing clearance for mid-to-large sized molecules combining diffusion and convection. Hemodiafiltration is a replacement renal therapy that enhances the removal of moderate molecular weight uremic toxins known to be implicated in the morbidity and mortality of ESRD patients (Van Laecke et al., 2006; Locatelli and Canaud, 2012; Locatelli et al., 2015). Enhancing convective removal of uremic toxins can help reduce complications of uremia.

In on-line HDF, correlation between convection volume and clinical outcome is critical. Convection volume is defined as the total ultrafiltration volume obtained over the entire HDF session. It is the sum of the replacement volume and the intradialytic weight loss achieved. Several studies have reported that a higher convection volume is associated with better clinical outcome (Mostovaya et al., 2015; Davenport et al., 2016).

Compared with conventional high-flux hemodialysis (HD), on-line HDF is associated with better control of anemia, nutritional status, treatment adequacy, hospitalization, greater reduction in calcium phosphate product, and higher elimination of parathyroid hormone (PTH). In addition, by infusing an ultrapure dialysate, on-line HDF can reduce inflammation and oxidative stress. Therefore, on-line HDF is superior to conventional high-flux HD for reducing morbidity and mortality. Numerous randomized studies have shown benefits of on-line HDF that is currently being conducted. However, no increase in long-term survival has been reported. The objective of this study was to compare long-term survival rate of patients receiving on-line HDF with that of patients treated with conventional high-flux HD by reviewing data from Chonnam National University Hospital (CNUH) (Vilar et al., 2009; Schmid and Schiffl, 2012; Grooteman et al., 2012; Potier et al., 2013; Mazairac et al., 2013).

\section{MATERIALS AND METHODS}

We selected patients who received treatment at the CUNH dialysis center who agreed to participate in this study. We selected those who started on-line HDF or conventional highflux HD with Helixone ${ }^{\circledR}$, a New High-Flux Polysulfone dialysis membrane changed to on-line HDF treatment. Patients aged $\geq 25$ years with end-stage renal disease (ESRD) receiving three-weekly HDF treatments for at least 3 months were included. Exclusion criteria were: age below 25, malignancy, or active systemic diseases. The control group was selected from patients who received conventional high-flux HD in our center with the same exclusion criteria.

Overall, 40 patients with ESRD switched from conventional high-flux HD to on-line HDF or started on-line HDF from August 2007 to December 2009. Additionally, a total of 42 patients receiving conventional high-flux HD during the same period were enrolled in this study. We then reviewed long-term survival rates for patients receiving on-line HDF over seven years. The follow-up study will enroll patients from when it was then check the status of 2015.

Vascular access of patients receiving on-line HDF was determined to be performed without the use of a single or temporary non-needle catheters tunnelized, through the AV fistula. Blood flow is important to the prevention of back filtration during on-line HDF. Maintaining blood flow rate will limit us to take advantage of on-line HDF which is faster for a certain speed according to the state and condition of the patient's vascular access. In our study, the blood flow rate was adjusted to have an average of $250 \mathrm{~mL} / \mathrm{min}$. On-line HDF mode was selected for pre-dilution hemodiafiltration due to its previously described advantages (Tiranathanagul et al., 2011; Maduell, 2015; Albalate Ramón et al., 2015; Akizawa and Koiwa, 2015).

Conventional high-flux HD was performed at a standard dose for 200 to 240 minutes, three times per week. Patients receiving on-line HDF had an average dialysis time of 3 to 4 hours. On-line HDF was started with convective exchange volume of $0.3 \mathrm{~L} / \mathrm{kg}$ of body weight and expanded to $0.8 \mathrm{~L} / \mathrm{kg}$ if tolerated by the patient. The convective exchange volume per $\mathrm{kg}$ (body weight) was increased until $0.8 \mathrm{~L} / \mathrm{kg}$. It was 
Table 1. Basal characteristics of patients

\begin{tabular}{lccc}
\hline \hline & $\begin{array}{c}\text { On-line HD } \\
(\mathrm{n}=40)\end{array}$ & $\begin{array}{c}\text { Conventional high-flux HD } \\
(\mathrm{n}=42)\end{array}$ & $\begin{array}{c}P \text {-value } \\
\text { Age (years) }\end{array}$ \\
Gender & $64 \pm 14.9$ & $65 \pm 14.4$ & 0.720 \\
$\quad$ Male) & $21(52.5 \%)$ & $19(45.2 \%)$ & \\
$\quad$ Female) & $19(47.5 \%)$ & $23(54.8 \%)$ & 0.138 \\
Duration before enrollment (years) & $2.5 \pm 0.5$ & $3.7 \pm 0.5$ & 0.688 \\
Body Weight (Kg) & $60.1 \pm 9.8$ & $59.3 \pm 8.9$ & 0.907 \\
BMI & $22.2 \pm 3.0$ & $22.2 \pm 2.8$ & 0.554 \\
Systolic blood pressure (mmHg) & $130.2 \pm 24.6$ & $133.2 \pm 21.9$ & 0.650 \\
Diasystolic blood pressure & $76.8 \pm 11.2$ & $78.0 \pm 11.2$ & $<0.001$ \\
Hemoglobin (g/dL) & $10.6 \pm 1.0$ & $10.1 \pm 1.0$ & 0.527 \\
Albumin (g/dL) & $3.91 \pm 0.28$ & $3.95 \pm 0.35$ & 0.330 \\
Total calcium (mg/dL) & $9.04 \pm 0.66$ & $8.93 \pm 0.78$ & 0.046 \\
Phosphate (mg/dL) & $4.10 \pm 1.35$ & $4.54 \pm 2.01$ & 0.322 \\
Potassium (mg/dL) & $4.82 \pm 0.65$ & $4.91 \pm 0.78$ & 0.163 \\
PTH (pg/mL) & $202 \pm 242$ & $247 \pm 330$ & 0.913 \\
Beta2-microglobulin (mg/L) & $1.41 \pm 0.18$ & $1.41 \pm 0.24$ & 0.913 \\
eKt/Vurea & $73.1 \pm 5.3$ & $73.8 \pm 6.2$ & 0.199 \\
URR (Urea reduction ratio) $(\%)$ & $73.1 \pm 5.3$ & $73.8 \pm 6.2$ & \\
\hline
\end{tabular}

then maintained. The mean final convective exchange volume was $0.77 \mathrm{~L} / \mathrm{kg}$ at the time of analysis. But that seems to have been set up there are still benefits from the rapid increase of on-line HDF and therefore, it should do on the adequacy of convection volume. Thus, we adjusted on-line HDF treatment adequacy according to total body water of patients.

\section{Statistics}

Difference between groups were compared by $t$-test. Difference in patient survival was analyzed by Kaplan-Meyers's method of mortality risk. A $P<0.05$ was considered statistically significant. All statistical analyses were conducted using SPSS version 18.

\section{RESULTS}

We compared two different groups to determine the survival rate to December 2015. Results are shown in Table 1. The 7-year survival rate of the group receiving on-line HDF was $65 \%$ while that of the group receiving conventional high-flux HD was 54.8\%, showing somewhat difference (Fig. 1). The 5-year survival rate of the on-line HDF group was $72.5 \%$ (Fig. 1) while that of the conventional high-flux HD group was $69.0 \%$, showing no significant difference between the two groups. The most frequent causes of death in the on-line HDF group were cardiovascular accident (n $=7)$, infection $(n=4)$, and cerebral hemorrhage $(n=3)$. In the conventional high-flux HD group, these were cerebral hemorrhage $(n=8)$, cardiovascular accident $(n=7)$, and infection $(n=4)$. For the cause of death, it was in a common cardiovascular event and cerebral hemorrhage in the group (Table 2).

\section{Anemia}

Overall, hemoglobin $(\mathrm{Hb})$ concentration was somewhat higher in the on-line HDF group (mean $\mathrm{Hb}, 10.6 \pm 1.0 \mathrm{~g} /$ $\mathrm{dL}$ ) than that in the conventional high-flux HD (mean $\mathrm{Hb}$, $10.1 \pm 1.0 \mathrm{~g} / \mathrm{dL}$, Table 1). Notably, hemoglobin concentration improved significantly after 32 weeks of on-line HDF $(10.6 \pm 0.9 \mathrm{~g} / \mathrm{dL})$ or conventional high-flux HD (10.2 \pm 


\begin{tabular}{|c|c|c|c|c|}
\hline \multirow[b]{2}{*}{ Status } & \multirow[b]{2}{*}{ N } & \multirow[b]{2}{*}{ Death } & \multicolumn{2}{|c|}{ Survival } \\
\hline & & & $\mathrm{N}$ & $\%$ \\
\hline Standard HD & 42 & 19 & 23 & $54.8 \%$ \\
\hline Online HDF & 40 & 14 & 26 & $65.0 \%$ \\
\hline Total & 82 & 33 & 49 & $59.8 \%$ \\
\hline
\end{tabular}

\begin{tabular}{|l|c|c|c|c|}
\hline & & & \multicolumn{2}{|c|}{ Survival } \\
\cline { 4 - 5 } Status & $\mathrm{N}$ & Death & $\mathrm{N}$ & $\%$ \\
\hline Standard HD & 42 & 13 & 29 & $69.0 \%$ \\
Online HDF & 40 & 11 & 29 & $72.5 \%$ \\
Total & 82 & 24 & 58 & $70.7 \%$ \\
\hline
\end{tabular}
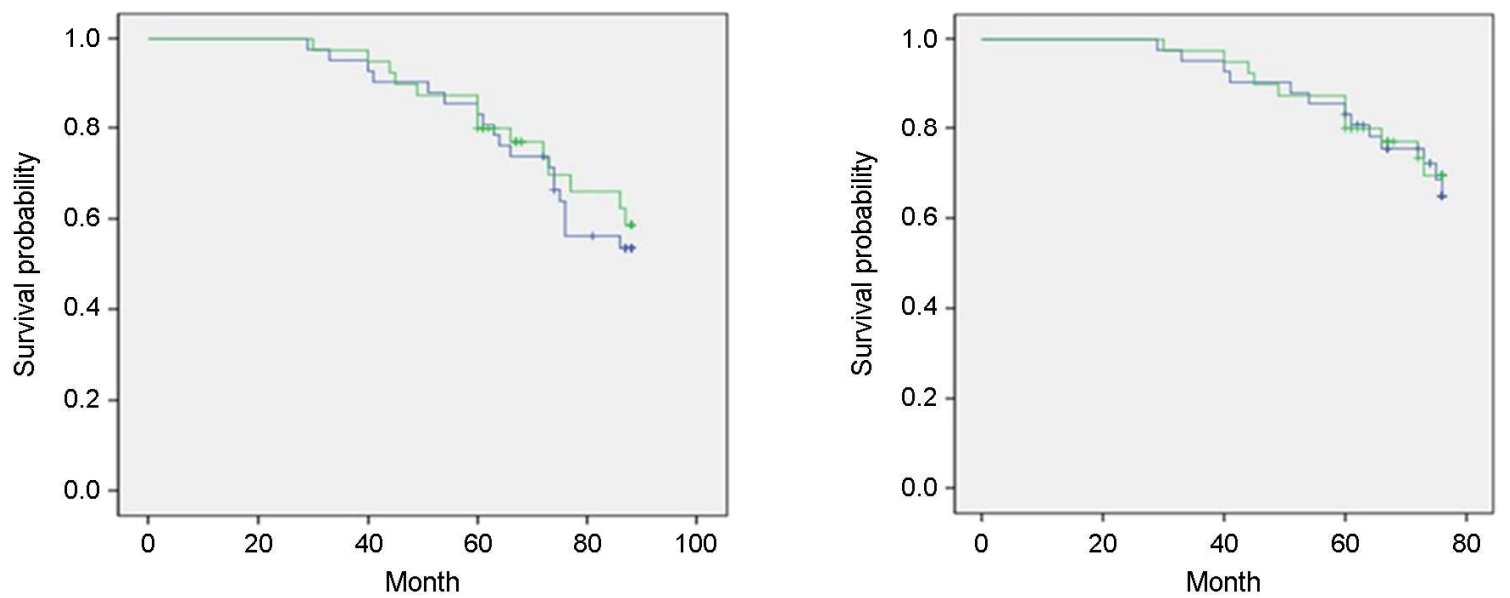

Fig. 1. Kaplan-Meyer plot of survival curves (7 years \& 5 years). The 7-year survival rate of the group receiving on-line HDF was $65 \%$ while that of the group receiving conventional high-flux HD was 54.8\%, showing somewhat difference. The 5-year survival rate of the on-line HDF group was $72.5 \%$ while that of the conventional high-flux HD group was $69.0 \%$, showing no significant difference between the two groups.

Table 2. Comparison of causes of death in two groups (on-line HD vs. conventional high-flux HD) over 7 years

\begin{tabular}{lcc}
\hline \hline & $\begin{array}{c}\text { On-line HD } \\
(\mathrm{n}=14)\end{array}$ & $\begin{array}{c}\text { Conventional } \\
\text { high-flux HD } \\
(\mathrm{n}=19)\end{array}$ \\
\hline Cardiovascular accident & $7(50 \%)$ & $7(36 \%)$ \\
Cerebral hemorrhage & $3(21 \%)$ & $8(42 \%)$ \\
Infection & $4(28 \%)$ & $4(21 \%)$ \\
\hline
\end{tabular}

$0.9 \mathrm{~g} / \mathrm{dL}$; Table 3). However, such improvement was not observed before 32 weeks. There was no significant difference in hemoglobin level between treatment groups when they were stratified by the presence of diabetes.

\section{Calcium-phosphate metabolism}

Total serum levels of calcium or PTH were not significantly different between before and after on-line HDF. However, serum phosphate concentration was somewhat lower in the on-line HDF group $(4.10 \pm 1.35 \mathrm{mg} / \mathrm{dL})$ than that in the conventional high-flux HD group $(4.54 \pm 2.01 \mathrm{mg} / \mathrm{dL}$; Table 1). Similar to $\mathrm{Hb}$ levels, phosphate concentrations of these two treatment groups differed when the duration of on-line HDF was more than 32 months (phosphorus level: $4.38 \pm 1.50 \mathrm{mg} / \mathrm{dL}$ in the conventional high-flux HD group vs. $3.87 \pm 1.10 \mathrm{mg} / \mathrm{dL}$ in the on-line HDF group, Table 3). However, they were not significantly different when the duration of online-HDF was less than 32 months.

\section{Nutritional status}

There was no significant difference in protein or albumin concentrations between conventional high-flux HD and online HDF groups (protein: $6.68 \pm 0.54 \mathrm{~g} / \mathrm{dL}$ vs. $6.64 \pm$ $0.50 \mathrm{~g} / \mathrm{dL}, P=0.354$; albumin: $3.95 \pm 0.35 \mathrm{~g} / \mathrm{dL}$ vs. 3.91 $\pm 0.28 \mathrm{~g} / \mathrm{dL}, P=0.527$, Table 1$)$. However, albumin concentration decreased somewhat with longer duration of online HDF $(4.04 \pm 0.29 \mathrm{~g} / \mathrm{dL}$ in the conventional high-flux HD group vs. $3.91 \pm 0.28 \mathrm{~g} / \mathrm{dL}$ in the on-line HDF group, Table 3). 


\section{Treatment adequacy}

There was no significant difference in eKT/V urea or Urea Reduction Ratio (URR) between conventional high-flux HD and on-line HDF groups. Furthermore, URR worsened when the duration of on-line HDF was more than 32 months (URR: $74.2 \pm 4.9$ for the conventional high-flux HD group vs. $72.5 \pm 5.6$ for the on-line HDF group, Table 3). Conversely, the level of $\beta 2$-microglobulin ( $\beta 2-\mathrm{m})$, a large weight molecular marker, was somewhat reduced in the on-line HDF group $(22.42 \pm 4.08 \mathrm{mg} / \mathrm{L})$ relative to the conven- tional high-flux HD group (24.02 $\pm 5.05 \mathrm{mg} / \mathrm{L}$, Table 2). Furthermore, more $\beta 2-\mathrm{m}$ was removed as the duration of on-line HDF increased (Table 3). A somewhat reduction in $\beta 2-\mathrm{m}$ level was observed in diabetic patients with on-line HDF ( $\beta 2-\mathrm{m}, 24.5 \pm 5.5 \mathrm{mg} / \mathrm{L}$ with conventional high-flux HD vs. $22.4 \pm 4.9 \mathrm{mg} / \mathrm{L}$ with on-line HDF, Table 4 ), but not in non-diabetic patients.

\section{Hospitalization}

Predominant reasons for hospitalization were infection, edema, and nutritional support. Before on-line HDF, the mean

Table 3. Comparison of various factors between conventional high-flux HD and on-line HDF groups depending on duration of on-line HDF

\begin{tabular}{|c|c|c|c|}
\hline & \multicolumn{2}{|c|}{ On-line HDF $\leq 32$ months $(\mathrm{n}=37)$} & \multirow{2}{*}{$P$-value } \\
\hline & On-line HD & Conventional high-flux HD & \\
\hline Hemoglobin (g/dL) & $10.6 \pm 1.1$ & $10.0 \pm 1.0$ & 0.10 \\
\hline Protein $(\mathrm{g} / \mathrm{dL})$ & $6.71 \pm 0.52$ & $6.60 \pm 0.62$ & 0.238 \\
\hline Albumin (g/dL) & $3.90 \pm 0.28$ & $3.82 \pm 0.38$ & 0.268 \\
\hline Total calcium (mg/dL) & $9.00 \pm 0.76$ & $8.87 \pm 0.93$ & 0.502 \\
\hline Phosphate (mg/dL) & $4.39 \pm 1.58$ & $4.74 \pm 2.53$ & 0.411 \\
\hline Potassium (mg/dL) & $4.84 \pm 0.70$ & $4.79 \pm 0.67$ & 0.740 \\
\hline PTH (pg/mL) & $200 \pm 196$ & $4.79 \pm 0.67$ & 0.068 \\
\hline Beta2-microglobulin (mg/L) & $22.6 \pm 3.0$ & $24.7 \pm 4.2$ & 0.073 \\
\hline eKt/Vurea & $1.43 \pm 0.19$ & $1.42 \pm 0.30$ & 0.771 \\
\hline \multirow[t]{3}{*}{ URR (Urea reduction ratio) (\%) } & $73.8 \pm 4.9$ & $73.3 \pm 7.7$ & 0.602 \\
\hline & \multicolumn{2}{|c|}{ On-line HD > 32 months $(\mathrm{n}=48)$} & \multirow{2}{*}{$P$-value } \\
\hline & On-line HD & Conventional high-flux HD & \\
\hline Hemoglobin (g/dL) & $10.6 \pm 0.9$ & $10.2 \pm 0.9$ & 0.004 \\
\hline Protein $(g / d L)$ & $6.59 \pm 0.49$ & $6.74 \pm 0.47$ & 0.053 \\
\hline Albumin $(g / d L)$ & $3.91 \pm 0.28$ & $4.04 \pm 0.29$ & 0.008 \\
\hline Total calcium (mg/dL) & $9.07 \pm 0.59$ & $8.98 \pm 0.65$ & 0.482 \\
\hline Phosphate (mg/dL) & $3.87 \pm 1.10$ & $4.38 \pm 1.50$ & 0.023 \\
\hline Potassium (mg/dL) & $4.80 \pm 0.62$ & $5.01 \pm 0.84$ & 0.149 \\
\hline PTH $(\mathrm{pg} / \mathrm{mL})$ & $204 \pm 275$ & $207 \pm 269$ & 0.935 \\
\hline Beta2-microglobulin (mg/L) & $22.3 \pm 4.4$ & $23.7 \pm 5.3$ & 0.028 \\
\hline eKt/Vurea & $1.39 \pm 0.18$ & $1.40 \pm 0.18$ & 0.613 \\
\hline URR (urea reduction ratio) (\%) & $72.5 \pm 5.6$ & $74.2 \pm 4.9$ & 0.008 \\
\hline
\end{tabular}

Table 4. Mean number of hospitalizations

\begin{tabular}{lccc}
\hline \hline & On-line HD & Conventional high-flux HD & $P$-value \\
\hline Number of hospitalizations & 1.47 & 4.44 & $<0.001$ \\
\hline
\end{tabular}


number of hospitalizations was 4.44. This was decreased to 1.47 after on-line HDF (Table 4).

\section{DISCUSSION}

The survival rate was somewhat higher in the on-line HDF group than that in the conventional high-flux HD group. However, it should be noted that this study had several limitations. Specifically, our data were based on a single center with a small number of subjects. Although large-scale patient studies are needed, the utilization rate of on-line HDF is low nationwide. Considering these facts, the number of patients in this study should be considered meaningful, although it was small. In addition, it is difficult to overlook benefits of significantly shorter survival after two hours of dialysis was started in on-line HDF group. This can be solved if we have more time. A lot of additional control group is also possible because the situation has been further increased in recent years for on-line HDF.

Even high cost compare to the high flux hemodialysis, the use of on-line HDF around the world has increased. And the number of studies showing its positive effects has grown. With reference to such studies, we can find current evidence for on-line HDF. The hemodialysis (HEMO) study was a large, multi-center, randomized controlled trial conducted in the United States to care patients randomly assigned to high-flux versus low-flux HD. No difference in survival was observed. However, a secondary analysis of patients who were on renal replacement therapy for $>3.7$ years showed significantly better survival in the high flux group (Canaud et al., 2006). The membrane permeability outcome study (MPO Study) was a large multi-center, controlled, randomized study conducted in Europe that included 738 HD incident patients. This study also failed to show beneficial effects of high-flux membranes on overall survival outcomes. In another specific study, the survival rate was regarded as the most important investigations are in progress for them. (Wizemann et al., 2000) have conducted a 24-month controlled prospective study in which 44 chronic dialysis patients are randomized to either low-flux HD or on-line HDF. They found no difference in morbidity. Although their study was similar in size to the present study, their follow-up period was short and no significant difference in survival rate was observed at one year (Wizemann et al., 2000). Two largescale studies (CONTRAST and ESHOL) were also conducted. However, with follow-up at an average of three years, on-line HDF failed to show benefit on survival (Maduell et al., 2011).

Over the past few decades, the survival rate of patients who underwent conventional high-flux HD in Korea has been improving slowly. The 5-year survival rate is now $70 \%$. However, the number of patients receiving on-line HDF is constantly increasing despite the lack of extensive studies on their long-term survival. Other studies did not show superiority of on-line HDF to conventional high-flux HD treatment for survival of patients.

As mentioned earlier, compared with conventional highflux HD, on-line HDF is associated with better control of anemia, nutritional status, treatment adequacy, and hospitalization as well as greater reduction in calcium phosphate product and higher elimination of parathyroid hormone (PTH). In addition, by infusing an ultrapure dialysate, on-line HDF can reduce inflammation and oxidative stress. Owing to these advantages, patients treated with on-line HDF is expected to show improved quality of life which will likely be reflected in an increase in survival rate.

In addition to research an on-line HDF from various angles, for example, convection volume is somewhat longer recognized, blood flow rate is appropriate figures were revealed through the study at any speed over whether, larger scale the relationship between these and on-line HDF. It is to be our challenge. If a greater convection volume is possible, on-line HDF will have an increased advantage over HD. Maintaining blood flow rate above a certain level will also be advantageous. However, considering that patient's vascular status is generally limited, not many studies have been conducted yet. The unusual present it to maintain high convection volume compared to other studies will also require further follow-up on this. It should be noted that on-line $\mathrm{HDF}$ also has several disadvantages. Its main disadvantage is cost. In order to keep the working costs a convection volume of that much. In addition, the exact relationship between on-line HDF and hypoalbuminemia observed in several studies is unknown. 
Overall, considering both disadvantages and benefits of on-line HDF as well as the long-term survival rate and number of clinical indicators, this treatment modality has shown a good effect. However, additional studies are needed to investigate long-term survival of patients in more centers.

\section{CONCLUSION}

Overall, the seven-year survival rate was higher in online HDF patients than that in conventional high-flux HD patients.

\section{ACKNOWLEDGEMENT}

None.

\section{CONFLICT OF INTEREST}

All authors have no competing interest to disclose.

\section{REFERENCES}

Akizawa T, Koiwa F. Clinical Expectation of Online Hemodiafiltration: A Japanese Perspective. Blood Purif. 2015. 40: 12 $-16$.

Albalate Ramón M, de Sequera Ortiz P, Pérez-García R, Corchete Prats E, Alcázar Arroyo R, Ortega Díaz M, Puerta Carretero $\mathrm{M}$. What is the optimum dialysate flow in post-dilution online haemodiafiltration? Neflologia. 2015. 35: 533-538.

Canaud B, Morena M, Leray-Moragues H, Chalabi L, Cristol JP. Overview of clinical studies in hemodiafiltration: what do we need now? Hemodial Int. 2006. 10: S5-S12.

Davenport A, Peters SA, Bots ML, Canaud B, Grooteman MP, Asci G, Locatelli F, Maduell F, Morena M, Nubé MJ, Ok E, Torres F, Woodward M, Blankestijn PJ; HDF Pooling Project Investigators. Higher convection volume exchange with online hemodiafiltration is associated with survival advantage for dialysis patients: the effect of adjustment for body size. Kidney Int. 2016. 89: 193-199.

Grooteman MP, van den Dorpel MA, Bots ML, Penne EL, van der Weerd NC, Mazairac AH, den Hoedt CH, van der Tweel I, Lévesque R, Nubé MJ, ter Wee PM, Blankestijn PJ; CONTRAST Investigators. Effect of Online Hemodiafiltration on All-Cause Mortality and Cardiovascular Outcomes. J Am Soc Nephrol. 2012. 23: 1087-1096.
Jean G, Hurot JM, Deleaval P, Mayor B, Lorriaux C. Onlinehaemodiafiltration vs. conventional haemodialysis: a crossover study. BMC Nephrol. 2015. 16: 70.

Jones JP, Leonard EF, Sandhu G, Winkel G, Levin NW, Cortell S. Daily ultrafiltration results in improved blood pressure control and more efficient removal of small molecules during hemodialysis. Blood Purif. 2012. 34: 325-331.

Locatelli F, Canaud B. Dialysis adequacy today: a European perspective. Nephrol Dial Transplant. 2012. 27: 3043-3048.

Locatelli F, Violo L, Longhi S, Del Vecchio L. Current Evidence in Haemodiafiltration. Blood Purif. 2015. 40: 24-29.

Maduell F. Is There an 'Optimal Dose' of Hemodiafiltration? Blood Purif. 2015. 40: 17-23.

Maduell F, Moreso F, Pons M, Ramos R, Mora-Macià J, Foraster A, Soler J, Galceran JM, Martinez-Castelao A. Online Hemodiafiltration Study Group from the Catalonian Society of Nephrology. J Nephrol. 2011. 24: 196-202.

Mazairac AH, Blankestijn PJ, Grooteman MP, Penne EL, van der Weerd NC, den Hoedt CH, Buskens E, van den Dorpel MA, ter Wee PM, Nubé MJ, Bots ML, de Wit GA; CONTRAST investigators. The cost-utility of haemodiafiltration versus haemodialysis in the Convective Transport Study. Nephol Dial Transplant. 2013. 28: 1865-1873.

Mostovaya IM, Grooteman MP, Basile C, Davenport A, de Roij van Zuijdewijn CL, Wanner C, Nubé MJ, Blankestijn PJ. High convection volume in online post-dilution haemodiafiltration: relevance, safety and costs. Clin Kidney J. 2015. 8: 368-373.

Moura A, Madureira J, Alija P, Fernandes JC, Oliveira JG, Lopez M, Filgueiras M, Amado L, Sameiro-Faria M, Miranda V, SantosSilva A, Costa E. Effect of Aging in the Perception of HealthRelated Quality of Life in End-Stage Renal Disease Patients under Online-Hemodiafiltration. Aging Dis. 2014. 6: 17-626.

Potier J, Le Roy F, Faucon JP, Besselièvre T, Renaudineau E, Farquet C, Soihan P, Touzard D, Djema A, Ilinca T. Elevated removal of middle molecules without significant albumin loss with mixed-dilution hemodiafiltration for patients unable to provide sufficient blood flow rates. Blood Purif. 2013. 36: 78 $-83$

Schmid H, Schiffl H. Hemodiafiltration and survival of end-stage renal disease patients: the long journey goes on. Int Urology Nephrol. 2012. 44: 1435-1440.

Smirnov AV, Nesterova OB, Suglobova ED, Golubev RV, Vasil'ev AN, Vasil'eva IA, Verbitskaia EV, Korosteleva NIu, Kostereva EM, Lebedeva EB, Levykina EN, Starosel'skiū KG, Lazeba VA. Clinical and laboratory evaluation of the efficiency of chronic 
hemodialysis treatment using acidosuccinate in patients with terminal renal failure. Ter Arkh. 2013. 85: 69-75.

Tiranathanagul K, Susantitaphong P, Towannang P, Injan P, Praditpornsilpa K, Eiam-Ong S. Measurement of vascular access flow by online clearance monitor in online hemodiafiltration. Blood Purif. 2011. 32: 195-201.

Van Laecke S, De Wilde K, Vanholder R. Online hemodiafiltration. Artif Organs. 2006. 30: 579-585.

Vilar E, Fry AC, Wellsted D, Tattersall JE, Greenwood RN, Farrington K. Long-Term Outcomes in Online Hemodiafiltration and High-Flux Hemodialysis: A Comparative Analysis.
Clin J Am Soc Nephrol. 2009. 4: 1944-1953.

Wizemann V, Lotz C, Techert F, Uthoff S. On-line haemodiafiltration versus low-flux haemodialysis. A prospective randomized study. Nephol Dial Transplant. 2000. 15: 43-48.

https://doi.org/10.15616/BSL.2019.25.1.32

Cite this article as: Yoon $\mathrm{JH}$, Kim NH. Seven-year Survival Rate of On-line Hemodiafiltration. Biomedical Science Letters. 2019. 25: 32-39. 